\title{
DIRECT ACCESS TO THE SUB-VENT BIOSPHERE BY SHALLOW DRILLING
}

BY JUN-ICHIRO ISHIBASHI, KATSUMI MARUMO, AKIHIKO MARUYAMA, AND TETSURO URABE

Studying hydrothermal systems by examining the seafloor alone only offers a two-dimensional view of a threedimensional system. Although technologically challenging, accessing the subsurface to directly sample rocks, microorganisms, and fluids beneath active hydrothermal fields is imperative. Conventional ship-based drilling seldom recovers intact the uppermost section of the seafloor that is most interesting for hydrothermal studies: the long ship-toseafloor drillstring is unstable until it has

JUN-ICHIRO ISHIBASHI (ishi@geo.kyushuu.ac.jp) is Associate Professor, Department of Earth and Planetary Sciences, Kyushu University, Fukuoka, Japan. KATSUMI MARUMO is Senior Researcher, Institute of Geology and Geoinformation, AIST, Tsukuba, Japan. AKIHIKO MARUYAMA is Senior Researcher, Research Institute for Biological Resources and Functions, AIST, Tsukuba, Japan. TETSURO URABE is Professor, Department of Earth and Planetary Sciences, University of Tokyo, Tokyo, Japan. penetrated at least several tens of meters into the seafloor. It is possible to avoid this problem by using a drilling system on the seafloor, although this, too, is fraught with challenges, including high temperatures, circulating hot water, and soft and bit-clogging sticky sediments.

Japanese scientists involved in the Archaean Park Project, an interdisciplinary program to study the interaction between the sub-vent biosphere and the geosphere in seafloor hydrothermal systems, deployed a drilling system called the Benthic Multi-Coring System (BMS) (Figure 1) at locations in the western Pacific Ocean from 2000 to 2005 , with support from the Japanese Ministry of Education, Science, and Technology (MEXT). BMS is a remotely operated seafloor coring system connected via an armored umbilical cable to a control console on the support ship R/V Hakurei-Maru No.2. BMS has a rotating storage magazine for the drilling equipment (core barrels, drilling rods, casing pipes) that enables it to core to depths of up to $20 \mathrm{~m}$ in 2.2-m intervals. BMS has five TV cameras to help search for appropriate drilling sites and for monitoring. The drill bit is cooled with seawater; for the Archaean Park Project we installed a large-volume, multi-step filtration system on the intake side of the cooling system to achieve aseptic drilling. Measurements of the high temperatures (up to $300^{\circ} \mathrm{C}$ ) within the boreholes were taken using a fully mechanical system embedded in the core barrel because electrical systems are not ideal in these conditions.

In total, we drilled 10 shallow holes at the Suiyo Seamount located in the Izu Bonin Arc in 2001-2002, and four holes in the southern Mariana Trough in 2003 during the Archaean Park Project. Core recoveries were not always good (6-90 percent), and penetration was limited (up to $10 \mathrm{~m}$ ); however, the core samples recovered showed direct evidence for hydrothermal alteration and mineralization (Figure 2). Analyses of the core samples yielded important 
Figure 1 (top). The Benthic MultiCoring System (BMS) ready for deployment aboard R/V Hakurei-Maru No. 2. Photo credit: Yoshinori Takano

Figure 2 (bottom). A core sample collected from the hydrothermal field in the southern Mariana Trough. Photo credit: Yoshinori Takano

geochemical information about the subsurface, especially with respect to the organic species present there. The holes produced by the BMS quickly developed into new artificial venting orifices, providing fluid sampling holes directly connected to the hydrothermal aquiferfrom which samples of unprecedented quality were taken - when the sites were revisited by submersible vehicles. Microbiological samples were extensively collected from the cores, the hydrothermal fluids, and the newly developed "in situ growth chamber" provided by the end of the casing pipe. They provided evidence of unique distribution patterns of microbes, including some new phylotypes.

Shallow drilling and scientific exploration of the hydrothermal subsurface is still in its infancy, but with equipment such as the BMS we can expect to recover the samples that will yield a more thorough understanding of this hidden ecosystem. 四
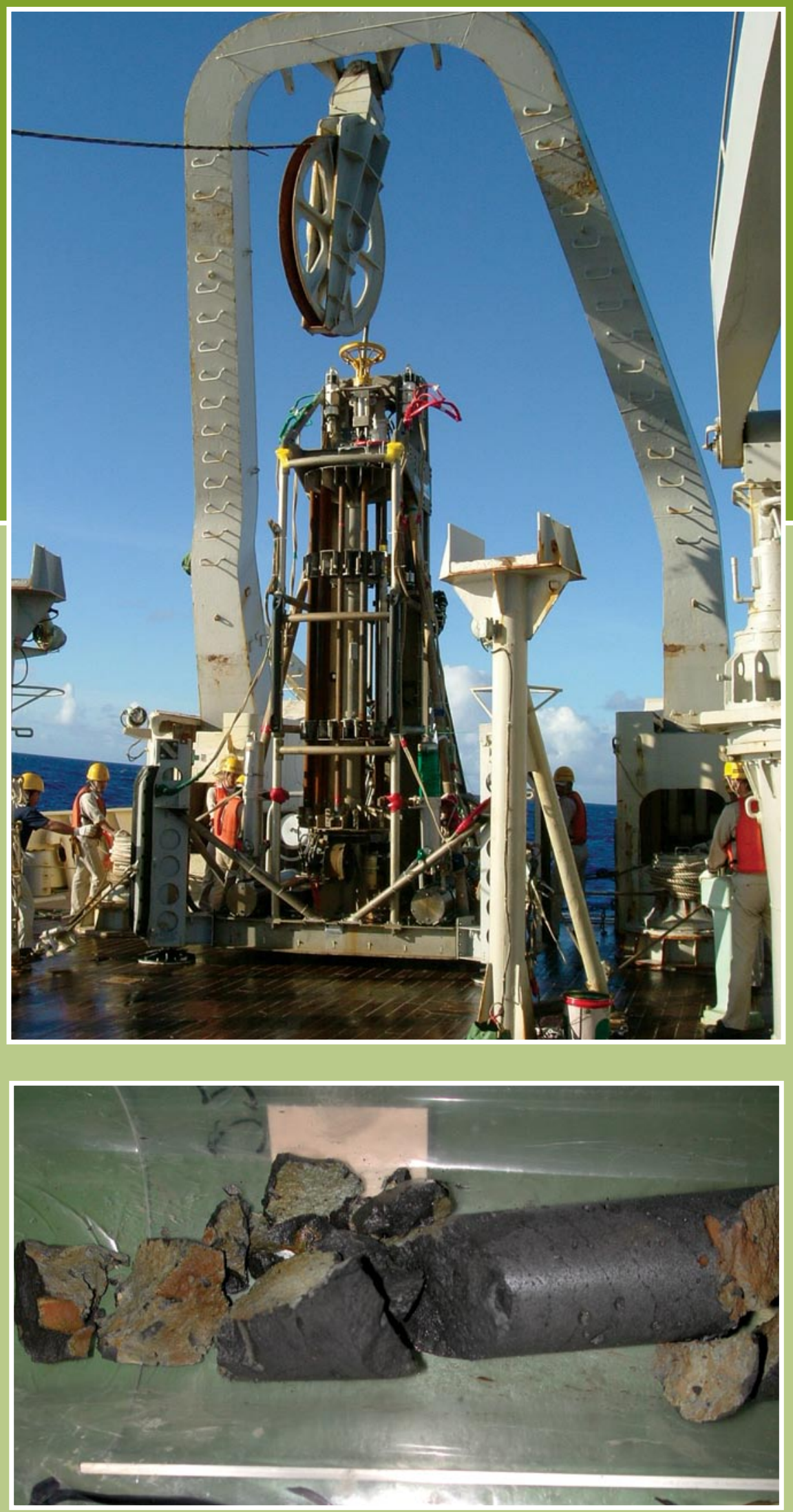